\title{
EL LUGAR DEL PATRIMONIO DOMINANTE
}

FRANCISCA MÁRQUEZ

VALENTINA ROZAS

RODOLFO ARRIAGADA

PROFESORA E INVESTIGADORA, DEPARTAMENTO DE ANTROPOLOGÍA, FACULTAD DE CIENCIAS SOCIALES, UNIVERSIDAD ALBERTO HURTADO, SANTIAGO, CHILE. PROFESORA E INVESTIGADORA, LABORATORIO CIUDAD Y TERRITORIO, UNIVERSIDAD DIEGO PORTALES, SANTIAGO, CHILE. ARQUITECTO Y MAGÍSTER EN DESARROLLO URBANO, PONTIFICIA UNIVERSIDAD CATÓLICA DE CHILE, SANTIAGO, CHILE.

\section{MONUMENTOS HISTÓRICOS NACIONALES} EN BUENOS AIRES Y SANTIAGO

A nte la pregunta por los idearios que dieron y dan forma a nuestras ciudades y que hacen de trasfondo a la vida urbana contemporánea, se propone un corpus conceptual que permita leer dichas representaciones a partir de los monumentos históricos nacionales de dos capitales latinoamericanas. De este modo, se sostiene que estos corpus patrimoniales dan forma al ordenamiento urbano, la materialidad arquitectónica, los cuerpos y las ideas en nuestras ciudades.

En estos términos, se afirma que la noción de patrimonio contenida en estos monumentos permite que los edificios actúen como mónadas, objetos que imponen y significan un cierto momento del pasado, de la memoria (Benjamin, 1973). A través de la significación de una forma arquitectónica, urbana o paisajística se instala la ciudad ideal. Ello hace que el concepto de patrimonio no sea jamás unívoco, sino una construcción social compleja, representativa de ideologías y prácticas sociales históricamente situadas. Este artículo ${ }^{1}$ aborda esta construcción y disputa en dos ciudades latinoamericanas: Buenos Aires de Argentina y Santiago de Chile. Las dos ciudades nacen en tiempos similares y contextos diferentes. Ambas ciudades, íconos del poder político surgen desde el deseo de proyectar un centro urbano para establecer el poder político que vele por los intereses de la nación. Como en tantas otras ciudades latinoamericanas, se evidencia el énfasis urbano del proceso de dominio del territorio americano (Almandoz, 2008).

Se parte de la premisa que la definición y declaratoria patrimonial contienen el ideario que da forma a nuestras ciudades. Definición e instauración que históricamente ha sido privilegio y tarea del Estado y su institucionalidad, tendiendo a una supuesta narrativa monolítica de la ciudad ideal. Contrario a la visión monolítica del discurso dominante, a modo de hipótesis, se plantea que a pesar de que la instauración y definición del patrimonio material continuaría siendo privilegio de la institucionalidad pública y que, por ende, estaría estrechamente vinculada a los intereses ideológicos y propios del ejercicio del poder de la autoridad pública, el ideario urbano no sería monolítico, sino producto de pugnas simbólicas dentro del poder hegemónico. Más allá de la permeabilidad en el discurso urbano dominante que han constituido los nuevos canales ciudadanos para el reconocimiento de patrimonios culturales e inmateriales diversos, esta hipótesis propone un quiebre interior a la hegemonía urbana del Estado, quiebre vehiculizado por la multiplicidad de voces contenidas dentro del propio aparato gubernamental. De esta manera, la investigación propone analizar los procesos de 'patrimonialización' de ambas capitales en cuanto reflejo de esta construcción nunca acabada.

En la búsqueda comprensiva de estas ciudades ideales, el camino elegido en esta investigación es la caracterización histórica de la forma del patrimonio material a través del relato público estatal. De este modo, para cada ciudad se abarca el periodo signado con la instauración de políticas patrimoniales: 1942 en Buenos Aires y 1951 en Santiago.

\section{ITINERARIO METODOLÓGICO}

El enfoque metodológico es cualitativo y se construye sobre la caracterización de la narrativa 'patrimonializante' del Estado en ambas ciudades. Para ello se sistematizan las declaratorias de Monumentos Históricos Nacionales (MHN) de dichas ciudades a lo largo de la historia. El estudio se centra en el análisis del monumento histórico nacional por dos razones: primero, contiene el discurso público sobre la monumentalidad en la historia nacional y, luego, permite comparaciones entre ambas ciudades.

Con objeto de responder a los objetivos de esta investigación, los MHN son organizados y sistematizados comparativamente según ciudad, fecha de construcción, fecha oficial de declaración patrimonial y tipología según uso. En el catastro total de monumentos en la ciudad de Santiago fueron identificados 147 elementos: 131 monumentos históricos nacionales (MHN) y 16 Zonas Típicas (ZT), aunque el análisis se enfoca principalmente en el primer grupo. A partir de la nómina nacional publicada por el Consejo de Monumentos Nacionales ${ }^{2}$, el criterio de selección se basó en aquellos ubicados en la provincia de Santiago de la Región Metropolitana. Asimismo, cabe señalar que existe una categoría paralela de monumento: el Inmueble de Conservación Histórica (ICH) que es declarado a nivel local mediante los Planes Reguladores Comunales (PRC). Ya que no forma parte del discurso hegemónico del Estado central, esta categoría no fue considerada en esta muestra.

En la ciudad de Buenos Aires la muestra total contiene 128 elementos: 122 monumentos históricos nacionales (MHN), un conjunto monumental conformado por cinco Bienes de Interés Histórico (BIH) y un Lugar Histórico Nacional (LHN). Al igual que en Santiago, el análisis se centra esencialmente en los MHN, sin embargo, los otros monumentos 
Una revisión de la lista de Monumentos Históricos Nacionales en dos ciudades plantea una caracterización de los discursos dominantes sobre el patrimonio, y revela que el debate sobre lugares patrimoniales ha sido un debate de las élites urbanas políticas y eclesiásticas.

PALABRAS CLAVE: URBANISMO, PATRIMONIO, MONUMENTO, SITIO PATRIMONIAL, BUENOS AIRES, SANTIAGO.
Reviewing the list of National Historic Landmarks in two Latin American cities poses a characterization of dominant discourses on heritage, and reveals that the debate on heritage sites has been an exclusive arena of the political and ecclesiastical urban elites.

KEYWORDS: URBANISM, HERITAGE, MONUMENT, HERITAGE SITE, BUENOS AIRES, SANTIAGO.

\section{FIG 1}

Distribución de Monumentos Históricos Nacionales y límites de casco histórico (línea roja).

Fuente: Elaboración propia, FONDECYT N 1120529.

\section{FIG 1A}

Santiago, Chile.

FIG 1B

Buenos Aires, Argentina.

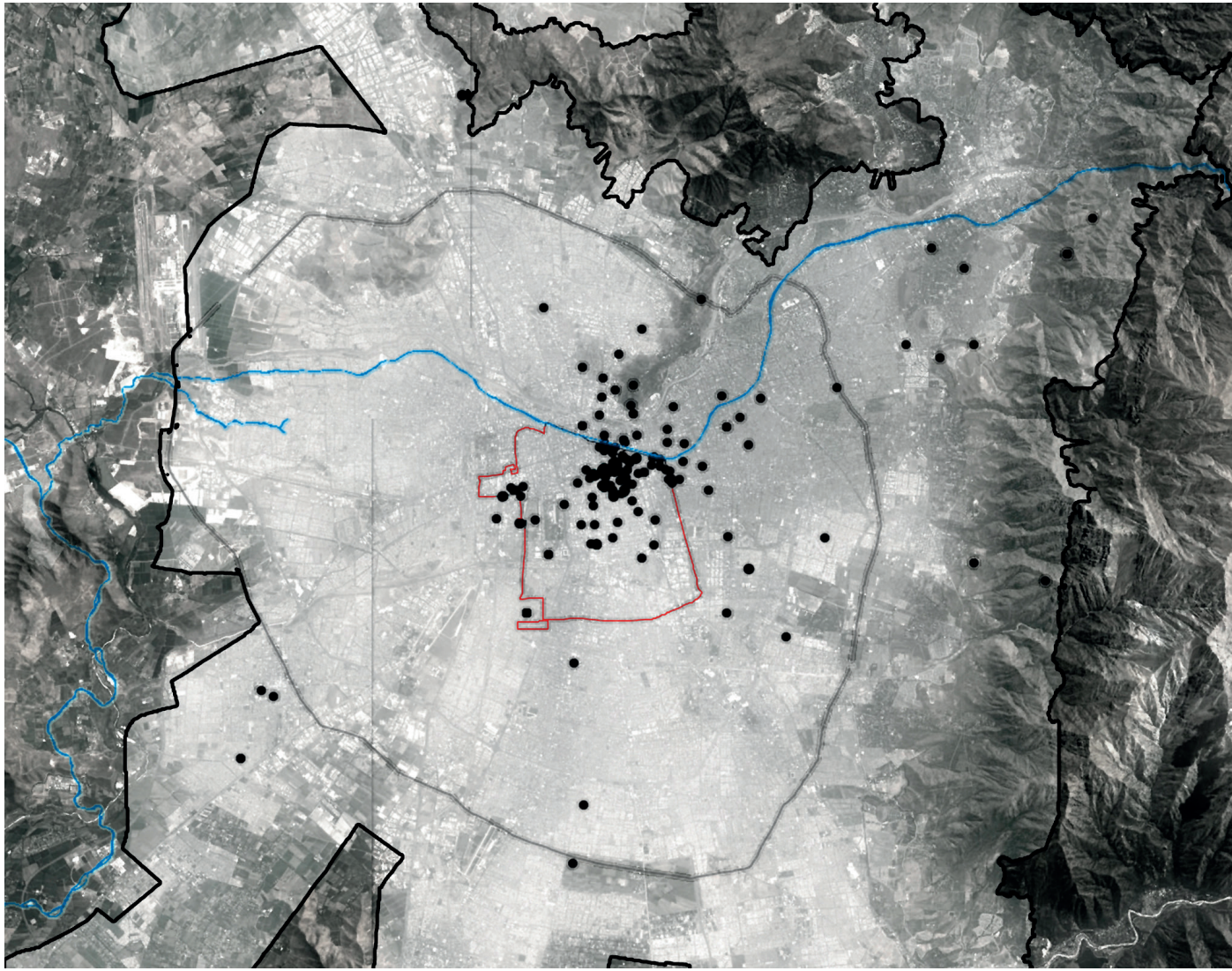

FIG 1A

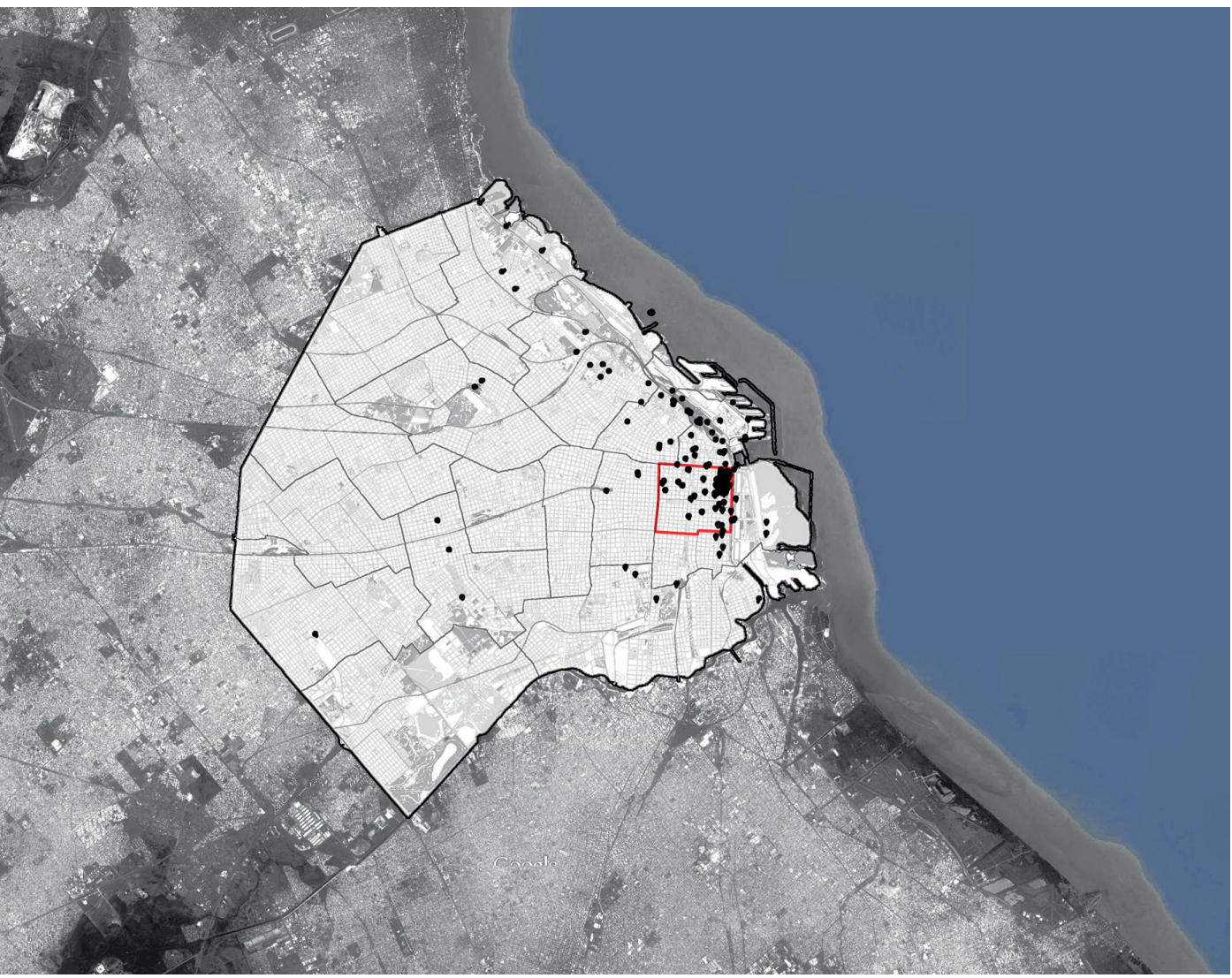




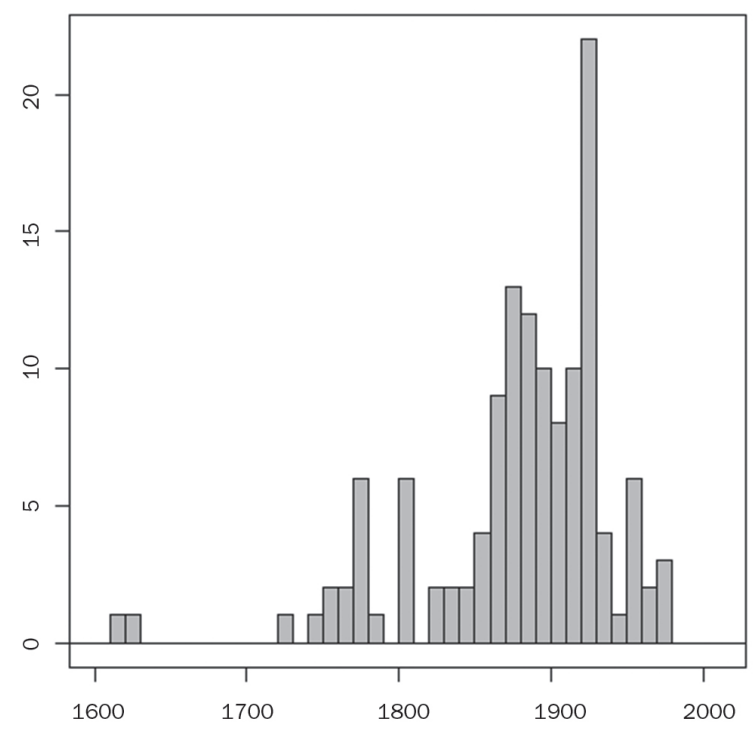

FIG 2A

contribuyeron a darle riqueza a la muestra. Los datos fueron recopilados a través de la Guía de Monumentos Nacionales de Argentina de 2008 y fue actualizada a la situación actual con la base electrónica de monumentos ${ }^{3}$ suministrada por la Comisión Nacional de Museos, Monumentos y Lugares Históricos. Fueron seleccionados aquellos monumentos nacionales ubicados administrativamente en la Provincia de Buenos Aires, en la localidad de Buenos Aires. De manera similar, el Código de Planeamiento Urbano (CPU) de Buenos Aires protege a nivel normativo ciertos inmuebles con interés patrimonial, pero fueron descartados aquellos que no son MHN, es decir, los que no cuentan con reconocimiento oficial a nivel nacional (ver figs. 1 y 2).

\section{VARIABLES DEL ANÁLISIS}

La variable del año de construcción para aquellos inmuebles que fueron construidos durante varios años, corresponde al año en que fueron inaugurados. Esta información fue conseguida analizando bases de datos y catálogos publicados por las instituciones mencionadas, el expediente de declaratoria y en algunos casos fue necesaria una indagación histórica más exhaustiva.

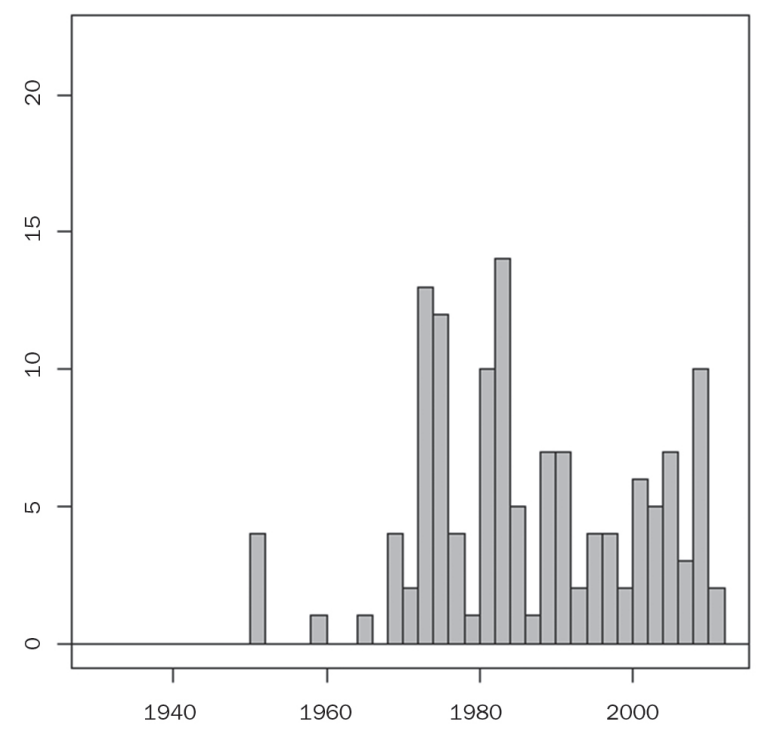

FIG 3A

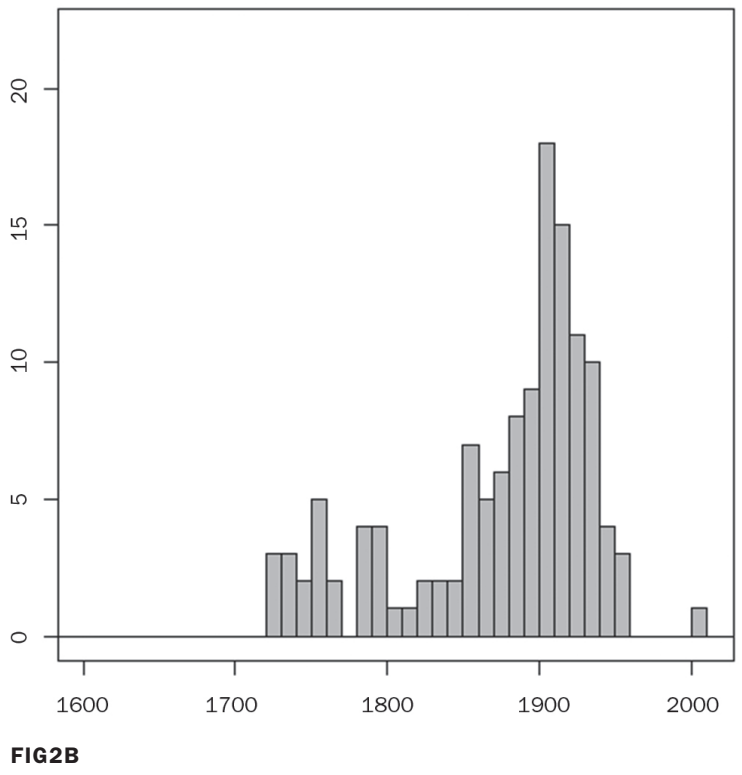

La clasificación según uso corresponde al destino original para el cual fue proyectado cada inmueble en su momento fundacional. Para ello se adapta la taxonomía propuesta por el Consejo de Monumentos Nacionales de Chile y se aplica a la muestra de ambas ciudades para hacer un análisis comparativo. Los datos fueron reunidos en tres macro grupos: equipamientos, vivienda y obras de Infraestructura. A su vez, los equipamientos fueron agrupados en las siguientes categorías: equipamientos religiosos y de culto; equipamientos fiscales y cívicos; equipamientos educacionales; equipamientos culturales; equipamientos financieros y bancarios; equipamientos vinculados a la memoria y los derechos humanos; y otros equipamientos.

Los gráficos que se presentan fueron desarrollados mediante el software $\mathrm{R}$, utilizado para el análisis e investigación estadística. Para ello se construyó una base de datos a partir del catastro patrimonial.

\section{IDEA, FORMA Y MONUMENTOS}

\section{EN LA CIUDAD FUNDACIONAL}

Preguntarse por los idearios e imaginarios de la ciudad exige preguntarse por las construcciones fundacionales que contribuyen o contribuyeron a hacer

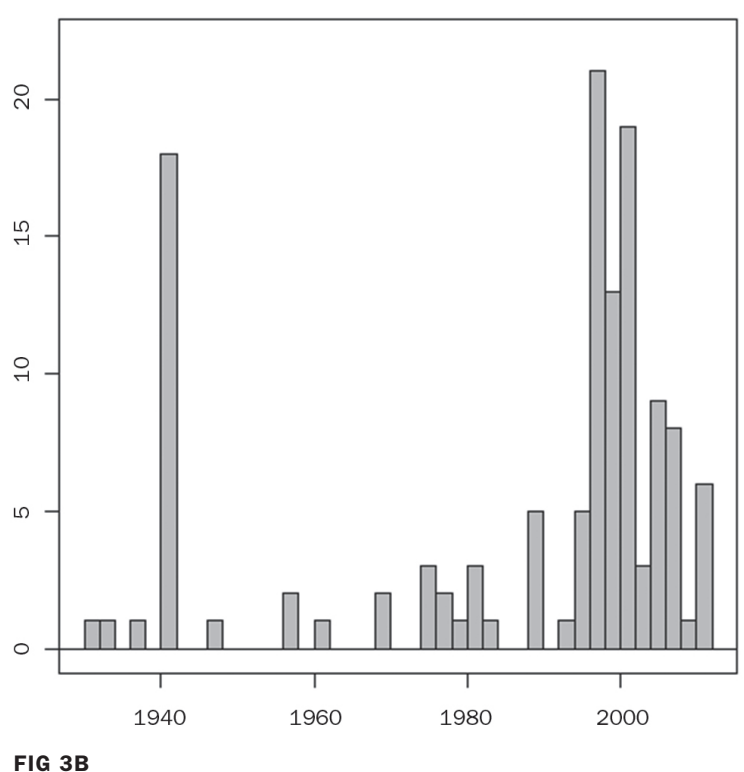


inteligible la experiencia de vida en ella. En estos términos, los imaginarios nos hablan de cómo los que habitan, los que piensan y los que escriben sobre la ciudad imaginan e inventan formas de vida urbana.

A toda historia urbana subyace una idea y una forma de ciudad. El hombre crea un lugar para el gobierno de los hombres, para la política (la polis) y para la cita de los citadinos (la civitas); pero al reunirse, ellos necesitan construir un lugar, un oikos o un locus y ello implica imaginar, delimitar y trazar un territorio. La ciudad, a través de la plaza, las calles y los monumentos públicos, centra y orienta tanto el conjunto de los cuerpos en el espacio, como los afanes políticos y cotidianos. Así, de esta forma se da cabida a la construcción utópica e histórica de cada ciudad y su destino (Márquez, 2008).

Como señala Bauman, la política es indisoluble de la ciudad y esta requiere siempre de un topos o lugar que le dé forma:

"Si la buena vida iba a ser un nuevo comienzo, parecía obvio que pidiera un nuevo lugar. Todas las buenas o malas formas conocidas de la vida, eran 'territoriales', como tenían que ser, en consecuencia, todos los planes para su mejora. La política, la actividad que tenía como objetivo el diseño, la protección, corrección y reparación de las condiciones bajo las cuales las personas persiguen sus propósitos de vida, deriva su nombre del término griego que significa 'ciudad' -y todo lo que la ciudad podría haber sido, siempre fue un lugar. Las identidades humanas, los derechos y las obligaciones humanas, así como las rutinas a seguir, las bonificaciones de seguirlos y las sanciones por violarlos, fueron todos territoriales. Contra viento y marea y, aparentemente, hasta que la muerte los separe, los destinos de la política y de los territorios estaban vinculados, de hecho, de manera inseparable" (2002, p. 54).

En Mesoamérica y Latinoamérica las ciudades nacen de ideas y formas diferenciadas, pero siempre de un ideario y utopía de ciudad ideal. El trazado del damero o la grilla es la estrategia formal de la conquista y fundación de las ciudades ideales, y a su vez representa el ejercicio de ordenamiento hegemónico de la conquista hispana (Gorelik, 1998; Durston, 1994). En este sentido, el ordenamiento coercitivo y el ordenamiento semántico del damero son dos dimensiones complementarias, casi indiferenciables del modelo. El damero actúa como un diagrama que impone determinadas relaciones de poder, pero al mismo tiempo es un modelo de estas relaciones. Por otra parte, el ordenamiento disciplinario del espacio que efectúa el damero está dirigido en gran medida a exponer a la población a un sistema de representaciones (Durston, 1994). A pesar de que las Leyes de India dictan las bases y medidas de la ciudad ideal, los conquistadores hispanos no diseñan las ciudades americanas siguiendo las leyes que sugerían manzanas rectangulares, sino que trazan las manzanas de forma cuadrada por ser una geometría más cercana a la perfección.
Sin embargo, a pesar de las voluntades de los fundadores, la gran mayoría de las ciudades fundacionales latinoamericanas pueden ser comprendidas y explicadas en términos de un diálogo entre trazado geométrico y condiciones geográficas. El trazado proporciona la base de la división de espacios públicos y privados, así como de la posterior subdivisión de la propiedad y la estructura fundamental sobre la cual se van sobreponiendo las edificaciones. Las condiciones geográficas, por su parte, cualifican la implantación de esta trama, determinan sus bordes y su figura, y afectan sus modos de desarrollo en el tiempo. Así ocurre en Buenos Aires y Santiago.

Para Adrián Gorelik, la grilla como conquista de la Pampa es la evidencia de la existencia de una voluntad política de planeamiento de la ciudad de Buenos Aires. Es la resolución formal de un trazado homogeneizador de toda la extensión de la ciudad que tiene el potencial de ofrecer un acceso equitativo a todos los ciudadanos a las bondades de la metrópolis. La cuadrícula representa entonces más que la estructura vial y predial de la ciudad, es una paradoja moderna: mientras que se articula como herramienta de cultura a través de la equidad territorial, al mismo tiempo es un recordatorio de lo sublime de la naturaleza al plantear la imposibilidad de abarcar la vastedad del territorio de la pampa argentina. Asimismo, la grilla representa una doble barbarie: es la reproducción anómala de la pampa bárbara por ser salvaje y la reproducción de la Ley de India que recuerda la barbarie del colonizador (Gorelik, 1998).

No solo la grilla se presenta como un elemento formal portador de los idearios y utopías de Buenos Aires, sino también el bulevar de circunvalación, actual Avenida General Paz, se convierte en una poderosa herramienta para dar forma y límite a la ciudad. Los deseos de una capital densa y vertical a la usanza europea requerían de un límite físico para su expansión. Sin embargo, aun cuando prima el deseo por la capital francesa, la influencia no se limita a su urbanismo y arquitectura, sino que se manifiesta en facetas plurieuropeas adecuadas a un contexto latinoamericano (Sarlo, 2008); "una ciudad europea, que se moderniza con empréstitos e infraestructura británicos, con criterios urbanístico franceses y con constructores italianos" (Gorelik, 1998, p. 28).

En Santiago la historia fundacional no es muy distinta. En ella, la cuadrícula fundacional también debe abrirse paso entre las condicionantes del territorio apoyado con un conjunto de calles que reflejan un reconocimiento de la topografía y el paso del río Mapocho. Santiago se funda junto a un curso de agua por la disponibilidad de este recurso para su consumo, riego de los campos de cultivo aledaños y para facilitar el drenaje de las aguas de lluvia. La ciudad en la falda andina entrecruza así las dos direcciones de su cuadrícula fundacional, que encuentra en las emergencias de los cerros el respaldo defensivo y la presencia paisajística que singulariza el emplazamiento (Gómez, 2009). A fines del siglo xIX el intendente Benjamín Vicuña Mackenna dio inicio a la primera remodelación global de Santiago, separando la ciudad patricia de la popular por medio de un 
camino de cintura. Así se da inicio a una incipiente segregación urbana y a un ideario de ciudad blanca y culta que mirará a Europa como su norte en la construcción de sus parques, edificios y monumentos.

\section{MONUMENTOS Y MEMORIA COLECTIVA}

Proponemos que en la noción de patrimonio material se contienen y expresan los idearios y narrativas dominantes de las utopías urbanas. La noción de patrimonio permite que los edificios actúen como mónadas u objetos que imponen y significan un cierto momento del pasado, la memoria y la utopía urbana (Nora, 1984-1992; Benjamin, 1973).

Por monumento entenderemos aquel objeto $\mathrm{u}$ artefacto edificado que interpela a la memoria, siendo esencial la naturaleza afectiva de su vocación, suscitando una memoria viva para recordar a generaciones anteriores, sus hechos y sus culturas (Choay, 1992).

Asimismo, el monumento histórico nacional (MHN) lo comprenderemos como una versión más específica del monumento en su acepción más general. Es decir, el MHN es también aquel objeto $u$ artefacto edificado que interpela y representa la historia nacional, pero valiéndose a menudo de la memoria viva y de los sentidos de la percepción a través de su forma y emplazamiento. En el monumento, el recuerdo del pasado como memoria o historia se actualiza en el presente a través de su forma y su estética, ambos convocan una identificación afectiva con una comunidad pasada.

Ello hace que el concepto de patrimonio no sea jamás unívoco, sino más bien una construcción social compleja representativa de ideologías y prácticas sociales históricamente situadas (Prats, 1997). Tradicionalmente la concepción de patrimonio ha sido aquella que lo define como monumento cerrado y susceptible de inventario (Saborido, 2010). Podríamos decir que las ciudades ideales y los imaginarios que las figuras patrimoniales alimentan también son una manera de salvarse de los horrores de la historia, de negar el tiempo y la muerte; a veces incluso a costa de un desesperado ejercicio de hipertrofia de la memoria (Durand, 1964; Lapouge, 1973; Brett, 1996; Rojas Mix, 2006).

Si bien el reconocimiento del valor patrimonial contiene una serie de sentidos compartidos, también deja fuera un amplio espectro de significaciones de grupos o segmentos sociales (Bloj, 1992; García Canclini, 1999). En Latinoamérica el patrimonio ha estado sometido a una dinámica social exclusivista y excluyente (Rabí, 2007). Exclusivista en cuanto a una apropiación disciplinaria e ilustrada del tema y excluyente en cuanto al acceso privilegiado a la formación, selección y apropiación de bienes culturales considerados patrimoniales que tienen unos sectores de la población. En palabras de García Canclini (1990), el patrimonio cultural funciona como un recurso para reproducir las diferencias entre los grupos sociales y la hegemonía de quienes logran un acceso preferencial a la producción y distribución de los bienes. Los grupos se apropian de formas diferentes y desiguales de la herencia cultural (Vidargas, 1997).

Las políticas patrimoniales que por mandato de Naciones Unidas se crean e instalan desde mediados del siglo Xx en nuestras ciudades, posibilitan la regularización de dichas definiciones y transparentan la disputa por los sentidos de la 'patrimonialización'. En estos términos, esta investigación propone que lo que se entiende como patrimonio al interior de nuestras ciudades constituye una disputa entre utopías hegemónicas a lo largo de la historia. Aún cuando nuestras ciudades latinoamericanas se pueblan de imaginarios y utopías excluyentes y exclusivas, esta investigación propone la existencia de narrativas diversas que se constituyen de relatos múltiples, diferenciados y cuyas narrativas de la ciudad abren nuevos campos de posibilidad a las ciudades ideales.

Los mecanismos provistos por la ley y la normativa regulatoria del patrimonio, hoy dejan abierta una puerta para que las expresiones ciudadanas se instalen y visibilicen (Rojas, 2001; ICOMOS, 1996). Es en esta línea que se propone indagar y contraponer las utopías que subyacen a las narrativas 'patrimonializantes', sus disputas y tensiones en la definición de la ciudad ideal.

\section{SANTIAGO, PATRIMONIO DE CIUDAD CENTRO}

En Santiago el imaginario de ciudad centro se funda en el doble papel que desempeñaba en el siglo XVI frente a las demás ciudades del país. Es decir, proveedora y sostenedora de la conquista, conquista, lugar de refugio, recreo y descanso, Santiago se convirtió en el arquetipo de tranquilidad y paz, el lugar más seguro del reino. Ello contribuyó a que se transformara para el resto del país, y para ella misma, en un modelo que todos miraban, imitaban y querían hacer suyo (De Ramón, 2007; De Mattos, 2006). Conforme lo revelan nuestras fuentes, el mito de la Ciudad de los Césares reaparece con fuerza en el Santiago ilustrado, rico y triunfal del primer centenario, tema sustentado por un mito de orden político no discutido. Urbe armoniosa que aún en el alba del siglo xx podía ser reconocida como una casa grande, imagen de una comunidad que celebra unida la dicha de una continuidad histórica armoniosa (Orrego Luco, 1908). El relato se empeñaba entonces en preservar un imaginario de ciudad homogénea que se deseaba hermosa, rica y feliz; una ciudad soñada (Franz, 2001), pero "en una sociedad radicalmente escindida como la de Santiago, esta historia tiene dos vertientes: la de la sociedad establecida, de la gente decente, y la de los sectores populares, los rotos" (Romero, 1976, p. 261).

Fue a mediados del siglo xIx que el reformismo burgués introduce con fuerza este imaginario utópico de una ciudad a imagen de París, ciudad de las luces (Gross, 1991). En el ideario del intendente Vicuña Mackenna, las huellas de la ciudad propia y la ciudad bárbara subsisten aún en el siglo XXI como formas diferenciadas del imaginario urbano. Un imaginario de ciudad propia que habla de modernidad, tiempos rápidos, zonificación, seguridad, vigilancia e higiene, pero esta ciudad convive también con imaginario(s) de frontera de la ciudad bárbara. Un ideario que se construye a pesar del Estado y el mercado desde el des-orden que le imprimen sus habitantes (Balandier, 1989). Mientras el ejercicio de 'patrimonialización' celebra y ordena ese imaginario de ciu- 
FIG 4

Monumentos Nacionales, correlación año de construcción versus año de declaratoria.

Fuente: Elaboración propia, FONDECYT No 1120529.

FIG 4A

Santiago, Chile.

FIG 4B

Buenos Aires, Argentina.
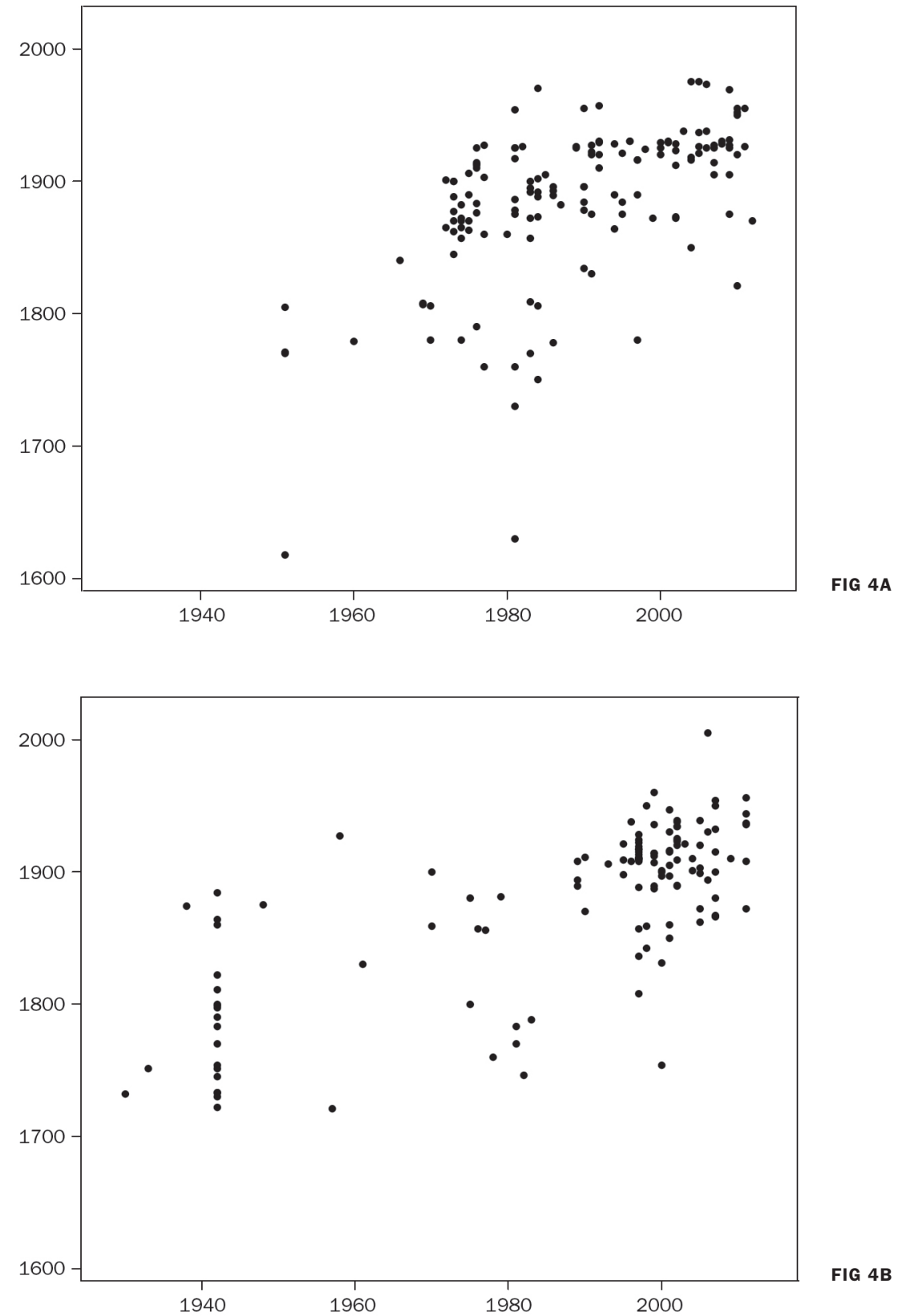

dad a semejanza del viejo ideario de la ciudad propia, las voces de sus ciudadanos abren esta imagen subvirtiéndola hacia las otras ciudades posibles.

A la fecha, la ciudad de Santiago cuenta con 147 lugares definidos como monumentos históricos nacionales, estando la mayor parte situados en el casco histórico de Santiago (Ballart y Tresserras, 2001). En Chile, el patrimonio urbano se rige mediante dos instrumentos legales normativos diferentes: la ley $\mathrm{N}^{\circ}$ 17.288 sobre monumentos nacionales que fue aprobada en 1970 en reemplazo de otra que existía desde 1925, correspondiente al Ministerio de Educación, y mediante la cual se han categorizados los monumentos nacionales; su protección la ejerce el Consejo de Monumentos Nacionales. El segundo, es la Ley General de Urbanismo y Construcciones a través del Ministerio de Vivienda y Urbanismo, que establece la creación de zonas e inmuebles de conservación histórica $^{4}$. Uno de los artículos más relevantes para los objetivos de este proyecto es el artículo $\mathrm{N}^{\circ} 10$ de la ley $\mathrm{N}^{\circ}$ 17.288 sobre monumentos nacionales. Esta señala que cualquier autoridad o persona puede denunciar por escrito ante el Consejo de Monumentos Nacionales la existencia de un bien mueble o inmueble que pueda ser considerado monumento histórico, indicando los antecedentes que permitirían declararlo tal. Es decir, aún cuando por ley es la institucionalidad pública quien sanciona y decide qué es o no patrimonio, el debate también se instala desde la ciudadanía que propone y abre la discusión sobre la definición y valorización del patrimonio.

\section{BUENOS AIRES, PATRIMONIO DE METRÓPOLIS EUROPEA}

Aunque los orígenes fundacionales de Buenos Aires tienen similitudes con la ciudad de Santiago así como con otras ciudades latinoamericanas, la capital argentina se constituye como metrópolis tensionada en su forma por el dominio del territorio y la creación de comunidad y sentido de nación (Gorelik, 1998; Outtes, 2002). Ambas figuras, la grilla como conquista del territorio de la pampa por el poder de la homogeneidad y el parque como el lugar de los relatos y redes de sentido, dan forma al ideario que constituye la Buenos Aires metropolitana (Gorelik, 1998; Welch Guerra, 2005). 


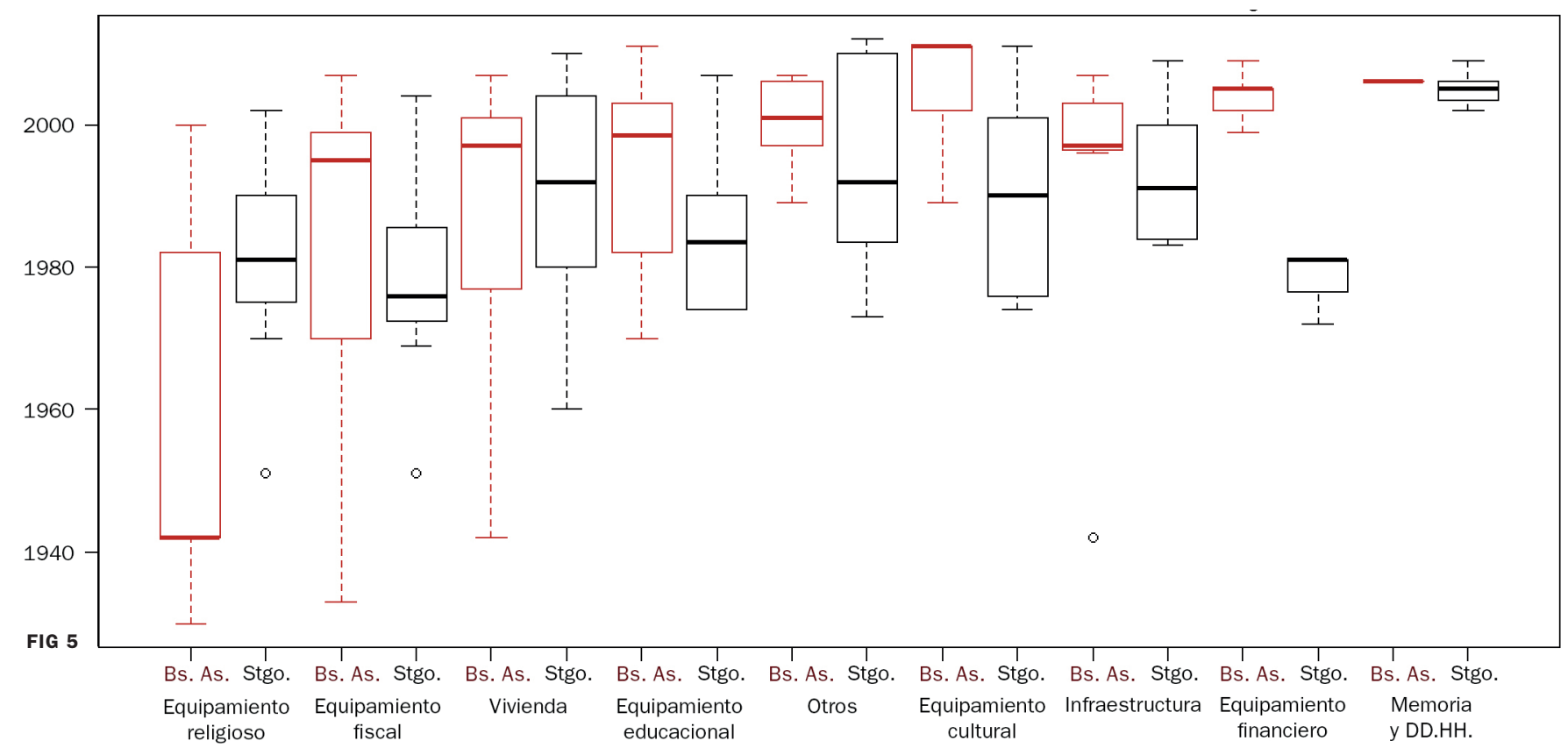

FIG 5

Monumentos Nacionales en Santiago y Buenos Aires, distribución del año de declaratoria versus uso.

Fuente: Rodolfo Arriagada Cura, elaboración propia, FONDECYT N ${ }^{\circ}$ 1120529
Disponible en: $<$ http://www.monumen- $\mathbf{6}$ tosysitios.gov.ar>, consultado el o1 Agosto 2012.

Extracto del Artículo 26 de la Ley 2506, 7 sancionada por la Legislatura de la Ciudad de Buenos Aires.

Nómina de monumentos nacionales 8 actualizada al 21 junio 2012. Disponible en: $<$ http://www.monumentos.cl>.
La hegemonía desplazada desde los españoles a las élites extranjeras transformaría a Buenos Aires en el depositario de sus anhelos europeos entre los siglos XIX y XX, convirtiéndola en el fragmento occidental y desarrollado de una América en proceso de civilización. "Erizada de torres, la ciudad proclama en la altura el vigor de un pueblo. Ya tiene la corona gris de las grandes metrópolis, gris de humo fundido con gris de nubes, como Londres, como París, como las gigantescas urbes del mundo; ese humo que se cierne hasta sobre las barriadas aristocráticas, hoy sacudidas también por el dinamismo característico del pueblo porteño" (Sarlo, 1988, p. 13). En la investigación sobre Buenos Aires imaginado de Armando Silva, la arquitectura y los espacios públicos son aquellas dimensiones más valoradas por el ciudadano porteño; el patrimonio habla de un proyecto de ciudad que pareciera ser alcanzado a través de su forma (Silva, 1996).

La institucionalidad gubernamental que opera en Buenos Aires relacionada con la identificación y protección patrimonial, puede agruparse en dos niveles: por un lado el gobierno de la nación Argentina y el gobierno de la ciudad de Buenos Airess. A través de la Legislatura de la Ciudad los monumentos históricos se sancionan con fuerza de ley. Ellos son reconocidos y propuestos por la Comisión Nacional de Museos y de Monumentos y de Lugares Históricos de la nación Argentina, institución de nivel nacional que depende de la Secretaria de la Presidencia del Gobierno de la nación. La Comisión Nacional de Museos y de Monumentos y Lugares Históricos ${ }^{6}$ fue creada en 1940 por la ley ${ }^{\circ} 12.665$, teniendo como objetivos: preservar, defender y acrecentar el patrimonio histórico y artístico de la nación, proponer la declaración de lugares y monumentos, inmuebles, documentos y ámbitos urbanos, entre otros.

Por su parte, el gobierno de la Ciudad [Autónoma] de Buenos Aires tiene a su cargo el Ministerio de Desarrollo Urbano, entre cuyas principales atribucio- nes se cuenta la planificación urbana, aunque entre ellas se considera proponer la catalogación y elaboración de normas urbanísticas y constructivas para los edificios y áreas que merezcan protección patrimonial, junto con su registro correspondiente ${ }^{7}$.

La Comisión para la Preservación del Patrimonio Histórico Cultural de la Ciudad de Buenos Aires fue creada por la ordenanza 41.081/86 y se integró formalmente el 11 de octubre de 1995. Al igual que en el caso de Chile, debe evaluar las solicitudes individuales de incorporación de edificios no catalogados, así como el grado de protección que estime correspondiente. Se abre entonces, al igual que para el caso de Santiago, un espacio a las expresiones individuales $\mathrm{y}$ al debate en relación a la ciudad patrimonial como expresión de un deseo de ciudad ideal.

\section{SITUAR LOS MONUMENTOS HISTÓRICOS NACIONALES}

Para el caso de Chile, el análisis se basa en la nómina oficial publicada por el Consejo de Monumentos Nacionales ${ }^{8}$. Se seleccionaron los monumentos históricos $(\mathrm{MH})$ para poder analizarlos con las categorías homólogas en el caso de Buenos Aires. Un segundo criterio está dado por la ubicación geográfica: fueron seleccionados aquellos elementos pertenecientes a la provincia de Santiago de la Región Metropolitana, y en especial aquellos pertenecientes al casco histórico de Santiago. En el caso de Buenos Aires se presentan aquellos del gran Buenos Aires y el análisis se focaliza en los monumentos históricos nacionales localizados en el casco histórico.

Una primera evidencia a partir del vaciado de los MHN en los planos de ambas ciudades, es que la gran mayoría se encuentra emplazada en el caso histórico y fundacional de ambas. La línea roja de estos mapas permite identificar la mayor concentración espacial de estos en el centro histórico y cívico. Aspecto que por cierto es congruente con el carácter 
histórico y nacional de dicha monumentalidad. El resto del universo de monumentos se diluye en las distintas direcciones, pero a mayor distancia del casco histórico, menor presencia y densidad de monumentos.

En relación al año de construcción de los monumentos históricos en ambas ciudades, los siguientes histogramas muestran comparativamente algunas diferencias (cuadro $\mathrm{N}^{\circ}$ 2). En el cuadro de la izquierda, correspondiente a Buenos Aires, se aprecia que los monumentos históricos pertenecen mayoritariamente a construcciones a partir del siglo XVIII en adelante, pero su declaratoria patrimonial se concentra en la primera década del siglo $\mathrm{XX}$ (1900-1910). Estos monumentos servirían de antesala al centenario de la Revolución de Mayo. Se observa también que no existen MHN oficialmente declarados por la Nación que hayan sido construidos en las últimas cuatro décadas del siglo Xx (1960200o). Algo distinto ocurre con los monumentos de derechos humanos y en especial aquellos declarados por el Gobierno de la Ciudad, como es el caso del Atlético.

En el caso de Santiago, la construcción de las edificaciones posteriormente reconocidas como monumentos se concentra significativamente en la segunda década del siglo xx (1920-1930). Del total de edificios, sólo se observan dos monumentos que fueron construidos a comienzos del siglo XVII, ambos correspondientes a iglesias. En tanto, la gran mayoría de los MHN fueron construidos después de las celebraciones del centenario de la primera Junta Nacional de Gobierno. En síntesis, en ambas ciudades los edificios construidos en el periodo conmemorativo del centenario de la independencia nacional son los que se privilegiarán para su 'patrimonialización'.

En el siguiente histograma se observa que en la ciudad de Buenos Aires las declaratorias patrimoniales comienzan con bastante anterioridad a las declaratorias ocurridas en la ciudad de Santiago (cuadro ${ }^{\circ}$ 2). En Buenos Aires se da inicio a la 'patrimonialización' oficial en 1938, con una mayor concentración en 1942 y los años noventa. En Argentina, el año 1942 durante el gobierno del presidente radical Roberto Ortiz y su vicepresidente Ramón Castillo, el Poder Ejecutivo argentino declaró mediante el decreto $\mathrm{N}^{\mathrm{O}} 12 \mathrm{O} 412$ una cantidad significativa de monumentos en la ciudad de Buenos Aires. En Santiago, ello comienza a ocurrir a mediados de 1950, esto es, en el gobierno del General Carlos Ibáñez del Campo. Las declaratorias, sin embargo, alcanzan una mayor concentración en los años ochenta, periodo de la dictadura militar, hecho coherente con el discurso ideológico nacionalista. Aún así, en términos generales, en Santiago no se observa una tendencia a la concentración de declaratorias patrimoniales.

Tal como se observa en el cuadro $\mathrm{N}^{\circ} 4$, las nubes muestran la correlación entre el año de construcción (eje vertical) y el año de declaratoria (eje horizontal) de los monumentos reconocidos oficialmente en Buenos Aires (izquierda) y Santiago (derecha). Esta correlación sintetiza lo señalado anteriormente. En efecto, en la ciudad de Buenos Aires se aprecian dos grandes periodos de declaratoria: una oleada de declaraciones del Poder Ejecutivo en 1942 (Decreto $\left.\mathrm{N}^{\mathrm{O}} 12 \mathrm{O} 412\right)$ y luego a partir de los años noventa. Este último grupo fue alentado por el incipiente Gobierno de la Ciudad de Buenos Aires, que apoya la presentación de expedientes de declaratoria nacional de una gran cantidad de monumentos emplazados al interior de su polígono administrativo.

En la ciudad de Santiago, en cambio, el reconocimiento patrimonial de monumentos se concentra recién a partir de la década de los setenta, aunque su tendencia de concentración es más dispersa en el tiempo. La lectura a partir de su año de construcción aporta una valiosa información: esencialmente, los monumentos reconocidos se aglomeran en torno a 1910-1925. De hecho, una mayoría significativa de los monumentos reconocidos en Santiago pertenecen al estilo neoclásico y afrancesado que reafirma el relato de una ciudad que en su centenario se deseaba moderna, refinada y culta, a semejanza de la ciudad de las luces, París. En síntesis, en ambas ciudades la mayor parte de los edificios patrimoniales son construidos en tiempos del centenario y oficializados como monumentos desde mediados del siglo xx en adelante.

El cuadro $\mathrm{N}^{\circ} 5$ caracteriza el uso de los monumentos patrimoniales según año de declaratoria. Un análisis de los primeros monumentos reconocidos oficialmente según su uso, muestra con claridad en ambas ciudades un proyecto de nación donde pugna el poder religioso con el poder político. En efecto, los primeros monumentos en ambas ciudades corresponden a las iglesias y catedrales de la ciudad fundacional y los centros del poder gubernamental. A medida que se avanza a lo largo del siglo xx se observa una diversificación en los usos de los monumentos reconocidos, nuevas tendencias que desembocan en la declaratoria de monumentos vinculados a la preservación de la memoria y la reivindicación de los derechos humanos a partir del siglo XXI.

Es interesante notar que para el caso de Buenos Aires son los edificios religiosos, fiscales, de vivienda y educacionales los que más presencia tienen a lo largo del tiempo en el universo de declaratorias patrimoniales. Pero son los edificios religiosos los que primeramente tienden a ser declarados monumentos históricos; concentrándose especialmente en la década del cuarenta.

En Santiago en cambio, predomina la diversidad de usos, marcando una leve tendencia en viviendas y equipamiento cultural. Los edificios religiosos comienzan a ser declarados monumentos muy posteriormente a Buenos Aires; recién a partir de los años setenta con la llegada del régimen militar. En general, las declaratorias en Santiago, independiente del uso del edificio, siempre son posteriores a las realizadas en Buenos Aires. La excepción la constituyen los edificios financieros y los memoriales de derechos humanos que comienzan a aparecer el año 2000 con el retorno a la democracia y las políticas de DDHH. 


\section{CONCLUSIONES}

Sabemos que la noción monolítica del patrimonio ha sido crecientemente discutida por la noción de patrimonio como bien de interés cultural, abierto y cambiante (Mosquera Adell, 1992). Es decir, como una noción que requiere alimentarse del interés y de la práctica ciudadana para legitimarse. Más aún, una noción que a pesar de los esfuerzos del Estado y el poder político por su hegemonía, siempre es objeto de disputa y controversia por voces subalternas y ciudadanas.

Sin embargo, los primeros resultados de esta investigación permiten señalar que la noción monolítica del patrimonio, articulada desde el poder, desde sus principios ha estado concentrada en la afirmación histórica de la nación y de la llamada religión civil al interior de la ciudad capital (Rousseau, 1762). Los monumentos históricos nacionales nacen desde la explícita voluntad de afirmar los valores que debiesen prevalecer en los ciudadanos de un Estado para permitir la perdurabilidad del pacto social. Los MHN actúan, en este sentido, como emblemas y nodos urbanos que, anclados en el centro fundacional de la ciudad, hacen de garantes de una memoria común y de la cohesión social. En su valor histórico, el monumento posee un carácter de documento, no tanto por lo que recuerda como por lo que enseña de la historia a través de su forma y su emplazamiento.

Las lecturas de los mapas de las ciudades de Santiago y Buenos Aires nos recuerdan que el lugar privilegiado de todo MHN es justamente el casco histórico y fundacional. La ciudad, en este sentido, es pensada como la sede material de la memoria colectiva; soporte desde donde el Estado adquiere su forma y su poder. Ciudad entonces, que permite las representaciones para la imagen colectiva del pasado y, al mismo tiempo, se constituye como un texto privilegiado de esa misma historia colectiva (Gorelik, 2011). De allí también que no deba extrañarnos que sean justamente los edificios construidos con objeto de la celebración de los centenarios de la República, quienes sean mayoritariamente objeto de 'patrimonialización'. Nombrarlos monumentos históricos y nacionales es darles el estatus histórico necesario para su perdurabilidad. Son los edificios institucionales, y en menor número religiosos, los llamados a conservar y resguardar esta historia de la nación. Sus usos originales pueden ser diversos, pero ellos siempre han sido pensados en tanto cimiento de una institucionalidad nacional.
Ciertamente, los procesos 'patrimonializantes' no son ajenos a las corrientes internacionales y sus mandatos de conservación y resguardo. No obstante, el recorrido de las declaratorias a los largo del siglo $\mathrm{xx}$ muestra que a menudo ellas van de la mano de gobiernos fuertes cuyos idearios son justamente la instalación y énfasis de un relato histórico nacionalista. Sin embargo, sabemos, y así lo señalan las primeras evidencias empíricas obtenidas del análisis de contenido de los expedientes patrimoniales, que a pesar de los esfuerzos del Estado por asentar dicho relato patrimonial, la discusión sobre los bienes patrimoniales también ha sido objeto de debate y tensión al interior de las élites y autoridades políticas. La historia, como sabemos, es lo que una sociedad decide como importante de su pasado, pero es obvio que esa decisión no puede ser pacífica ni tampoco monopolizada (Gorelik, 2011).

La reciente apertura de las discusiones patrimoniales hacia la ciudadanía ha significado una democratización del proceso de selección y definición del carácter monumental de los edificios de la ciudad. La definición de los objetos y edificios merecedores de la categoría de monumento histórico nacional ha sido un asunto que ha preocupado históricamente al poder; y las primeras evidencias empíricas de esta investigación señalan que los resultados de dicha disputa contienen los idearios e ideologías de su tiempo. De allí entonces que nuestras ciudades contemporáneas continúen y posiblemente sigan vistiéndose de monumentalidad en su acepción dominante y excluyente, haciendo de la producción y apropiación ciudadana una disputa permanente.

La tarea es entonces preguntarse bajo qué condiciones políticas, sociales y estéticas se construyen y transforman los idearios que sostienen esta monumentalidad hegemónica en nuestras ciudades. Ciertamente hay condiciones sociales e históricas más favorables que otras para que determinados idearios sean instituidos e impuestos socialmente, pero sabemos también que el discurso triunfante no siempre fagocita toda la diversidad de relatos e idearios; nuestras ciudades, por definición, son escenarios de coexistencia de culturas e identidades diversas (Simmel, 1986). El reconocimiento de estas capacidades de idearios y utopías múltiples, incluidas las del poder hegemónico, permitirá avanzar hacia la comprensión de las pertenencias y afectos a las ciudades, sus formas e ideas. ARQ 


\section{REFERENCIAS BIBLIOGRÁFICAS}

ALMANDOZ, Arturo. "Despegues sin madurez. Urbanización, industrialización y desarrollo en la Latinoamérica del siglo XX". Revista EURE, 34 (102): 61-76, agosto de 2008. BALANDIER, Georges. El desorden: la teoría del caos y las ciencias sociales. Elogio de la fecundidad del movimiento. Original de 1989; Segunda edición. Barcelona, Gedisa, 1994.

BALLART, Josep y TRESSERRAS, Jordi Juan I. Gestión del patrimonio cultural. Barcelona, Ariel, 2001.

BAUMAN, Zygmunt. La sociedad sitiada. Original de 2002. México, Fondo de Cultura Económica, 2004. BENJAMIN, Walter. Discursos interrumpidos. Madrid, Taurus, 1973.

BLOJ, Cristina. "De la identidad y sus espacios. Impronta de lugar, identidad y espacialidad". Estudios Sociales, (3): 41-48, 1992.

BRETT, David. The Construction of Heritage. Cork, Cork University Press, 1996.

CHOAY, Françoise. Alegoría del patrimonio. Original de 1992. Barcelona, Gustavo Gili, 2007.

DE MATTOS, Carlos et al (eds.). Huellas de una metamorfosis me tropolitana 1970/2000. Santiago, Instituto de Estudios Urbanos y Territoriales, Pontificia Universidad Católica de Chile, 2006. DE RAMÓN, Armando. Santiago de Chile: (1541-1991): historia de una sociedad urbana. Santiago, Catalonia, 2007.

DURAND, Gilbert. L'imagination symbolique. Original de 1964. Tercera edición. París, Presses Universitaires de France, 1976. DURSTON, Alan. "Un régimen urbanístico en la América Hispano colonial: un trazado de damero durante los siglos XVI y XVII". Revista Historia, (28): 59-115, 1994.

FRANZ, Carlos. La muralla enterrada: (Santiago, ciudad imaginaria). Santiago, Planeta, 2001

GARCÍA CANCLINI, Néstor. Culturas híbridas: estrategias para entrar y salir de la modernidad. Original de 1990. Buenos Aires, Paidós, 2001.

GARCÍA CANCLINI, Néstor. "Los usos sociales del Patrimonio Cultural”. En: Aguilar Criado, Encarnación (coord.). Patrimonio Etnológico. Nuevas perspectiva de estudio. Granada, Consejería de Cultura, Instituto Andaluz del Patrimonio Histórico y Editorial Comares, 1999. p. 16-33.

GÓMEZ, José Luis. "Ríos de ideas". ARQ, (72): 32-37, agosto de 2009.

GORELIK, Adrián. "La memoria material: ciudad e historia".

Boletín del Instituto de Historia Argentina y Americana Dr. Emilio Ravignani, (33): 1-6, 2011.

GORELIK, Adrián. La grilla y el parque: espacio público y cultura urbana en Buenos Aires, 1887-1936. Buenos Aires, Universidad Nacional de Quilmes, 1998.

GROSS, Patricio. "Santiago de Chile (1925-1990): planificación urbana y modelos políticos". Revista EURE, 17 (52-53): 27-52, 1991.

ICOMOS-INTERNATIONAL COUNCIL OF MONUMENTS AND SITES. Memorias del seminario sobre la conservación del patrimonio del siglo XX. México, ICOMOS -UAM Xochimilco, 1996.

LAPOUGE, Gilles. Utopie et civilizations. Original de 1973. París, Albin Michel, 1990.

MÁRQUEZ, Jaime. Idea y forma en las ciudades: breve revisión histórica de la idea y la forma de ciudad en Europa y América. [Apuntes de clase]. Santiago, Universidad Academia Humanismo Cristiano, 2008

MOSQUERA ADELL, Eduardo. "De la utilidad de la arquitectura para el patrimonio". En: MARTIN, Marcelo (coord.). Arquitectura y patrimonio. Memoria del futuro. Una reflexión sobre la relación entre patrimonio y arquitectura. Sevilla, Instituto Andaluz del Patrimonio Histórico. Junta de Andalucía, 1992. p. 16-28. NORA, Pierre. Pierre Nora en los lugares de memoria. Selección sobre original de 1984-1992. Santiago, LOM, 2009.

ORREGO LUCO, Luis. Casa grande. Original de 1908. Santiago, Andrés Bello, 1983.

OUTTES, Joel. "Disciplinando la sociedad a través de la ciudad: el origen del urbanismo en Argentina y Brasil (1894-1945)". Revista EURE, 28 (83): 7-29, mayo de 2002.

PRATS, Llorenc. Antropología y patrimonio. Barcelona, Ariel, 1997.

RABÍ, Salim. "Habitar, cuál patrimonio?”. En: HALPERT, Mirtha (ed.). Habitar el patrimonio. Santiago, Universidad Central de Chile, 2007. p. 45-49.

ROJAS, Eduardo (ed.). Una obra en marcha: el Banco Interamericano de Desarrollo y la protección del patrimonio cultural. Washington D.C., BID, 2001
ROJAS MIX, Miguel. El imaginario: civilización y cultura del siglo XXI. Buenos Aires, Prometeo Libros, 2006.

ROMERO, José Luis. Latinoamérica: las ciudades y las ideas. Original de 1976. Buenos Aires, Siglo Veintiuno, 2001. ROUSSEAU, Jean-Jacques. El contrato social. Original de 1762. Barcelona, Editorial ISTMO, 2004.

SABORIDO Marisol. "Repensar el patrimonio cultural... (A propó sito del terremoto)". Temas Sociales, (67): 1-8, mayo de 2010 SARLO, Beatriz. "Cultural Landscapes: Buenos Aires from Integra tion to Fracture". En: Huyssen. Andreas (ed.). Other cities, other worlds. Urban Imaginaries in a Globalizing Age. Durham, Duke University Press, 2008

SARLO, Beatriz. Una modernidad periférica: Buenos Aires 1920 y 1930. Buenos Aires, Nueva Visión, 1988.

SILVA, Armando. "Rito urbano e inscripciones imaginarias en América Latina”. Persona y Sociedad, X (1): 106-115, abril de 1996.

SIMMEL, Georg. "Las grandes urbes y la vida del espíritu". En su: El individuo y la libertad: ensayos de crítica de la cultura. Barcelona, Península, 1986. p. 247-262.

VIDARGAS, Francisco (comp.). La sociedad civil frente al patrimonio cultural. México, IIE-UNAM, 1997.

WELCH GUERRA, Max (ed.). Buenos Aires a la deriva: transformaciones urbanas recientes. Buenos Aires, Biblos, 2005.

\section{BIBLIOGRAFÍA}

CÁCERES, Gonzalo. “Modernización autoritaria y renovación del espacio urbano: Santiago de Chile, 1927-1931". Revista EURE, 21 (62): 99-108, abril de 1995.

CHOAY, Françoise. El urbanismo: utopías y realidades. Original de 1965. Barcelona, Lumen, 1970.

GORELIK, Adrián. "Historia de la ciudad e historia intelectual". Prismas, Revista de historia intelectual, (3): 209-223, 1999. MERINO, Roberto. Santiago de memoria. Santiago, Planeta, 1997. SARLO, Beatriz. La ciudad vista: mercancías y cultura urbana. Buenos Aires, Siglo Veintiuno, 2009.

FRANCISCA MÁRQUEZ | Antropóloga, Universidad de Chile, 1986; Máster en Desarrollo Social y Económico, Universidad Católica de Lovaina, 1993; Doctora en Sociología, Universidad Católica de Lovaina, 2005. Ha dirigido diversas investigaciones del Fondo de Ciencias y Tecnología en Chile y ha publicado trabajos sobre identidades urbanas, imaginarios y desigualdad en América Latina. Hasta el año 2014 fue decana de la Facultad de Ciencias Sociales de la Universidad Alberto Hurtado. Se desempeñó como investigadora en SUR, Centro de Estudios Sociales y Educación entre 1986 y 2000; fue presidenta del Colegio de Antropólogos de Chile entre 2004 y 2007; vicepresidenta de la Fundación Nacional para la Superación de la Pobreza entre 2004 y 2008, y directora del Grupo de Estudios Antropología y Arqueología de CONICYT EN LOS años 2009 y 2010.

VALENTINA ROZAS | Arquitecta y Magíster en Desarrollo Urbano, Pontificia Universidad Católica de Chile, 2011. Actualmente es estudiante del programa de doctorado en Arquitectura y Estudios Urbanos de la Universidad de California, Berkeley. En 2014, junto a RIL editores, publicó el libro "Ni tan elefante: ni tan blanco" basado en su tesis de magíster sobre la historia del Estadio Nacional de Santiago. En el 2008 obtuvo el primer lugar en el concurso de arquitectura para el patio 29 del Cementerio General de Santiago, organizado por el Consejo de Monumentos Nacionales. Aquel proyecto fue seleccionado para participar del pabellón chileno de la Bienal de Urbanismo y Arquitectura de Shenzhen-Hong Kong de 2011 y además ganó el premio de selección del jurado en la Bienal de Arquitectura y Territorio de Santiago de 2012. Durante 2011 fundó el colectivo MEMOPOLIS junto a Rodrigo Millán. Ese mismo año, junto a Teodoro Fernández Arquitectos y Danilo Martic obtuvo el primer lugar en el concurso "Parque de la ciudadanía” para el Estadio Nacional de Santiago.

RODOLFO ARRIAGADA | Arquitecto y Magíster en Desarrollo Urbano, Pontificia Universidad Católica, 2011. Recibió el premio a la Excelencia Académica Padre Hurtado entre 2004 y 2009. En el 2010 recibió la beca de Matrícula para Estudios de Magíster de la Facultad de Arquitectura, Diseño y Estudios Urbanos. Su línea de investigación ha interrogado la dialéctica entre recupe ración patrimonial y desarrollo sustentable en la planificación urbana con trabajo de campo en Chile, Argentina y Brasil. Trabajó modelando fenómenos espaciales en ciudades chilenas en el Ministerio de Vivienda y Urbanismo del Gobierno de Chile. 